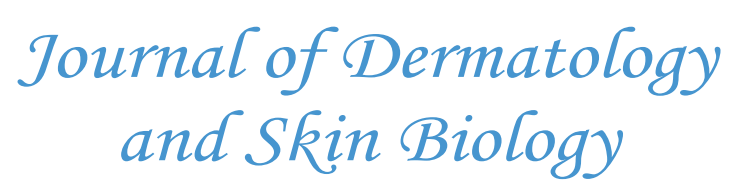

Editorial

\title{
The Skin: A Mirror Reflecting Neuro-Psychiatric Disorders
}

\author{
Mustafa Afifi* \\ Community Medicine Department, RAK College of Medical Sciences, UAE.
}

\section{Received Date: April 16, $2015 \quad$ Accepted Date: April 23, $2015 \quad$ Published Date: April 28, 2015}

*Corresponding author: Afifi, M. Community Medicine Department, RAK College of Medical Sciences, UAE. E-mail: afifidr@gmail.com

Citation: Afifi, M. The Skin: A Mirror Reflecting Neuro-Psychiatric Disorders. (2015) J Dermatol Skin Biol 1(1): 5- 6.

\section{Editorial}

Many papers were published from mid 60s till date with the key word "skin" and "mirror" in its title ${ }^{[1-16]}$.

Actually doctors of all clinical specialties understand that the skin is a mirror of many diseases as celiac diseases, polyposis syndromes, and intestinal malignancies. And, as GI diseases can have a dermatological manifestation, GI tract can be involved in many dermatological disorders as vesicobullous disorders $^{[1,7,8,12]}$. Skin also mirrors bone marrow ${ }^{[6,16]}$ and reflect some malignancies ${ }^{[14]}$. Immunological and rheumatic diseases could also show signs on our $\operatorname{skin}^{[10-11]}$. Diabetes mellitus is a major health problem in Gulf countries. Muco-cutaneous lesions are associated with diabetes. Skin manifestation of diabetes should be common to be missed by practioners. They can take credit for both detecting DM and facilitating early diagnosis of its complications ${ }^{[2]}$.

Moreover, researchers studied the role of certain neuro-transmitters on skin which is also the mirror of souls ${ }^{[5-9]}$. The mammalian skin is both a site for the production of and a target for bioregulation by serotonin (5-HT). General practitioners, dermatologists, and psychiatrists should be alert to a some skin lesions common with patients on antidepressants with the indication of their clinical monitoring and management ${ }^{[17-18]}$.

Parkinson's disease is a chronic neurodegenerative disorder that is expected to increase in coming decades as the Arab population survival becomes longer. Dermatological disorders were also being recognized with Parkinson's disease, yet are often overlooked. Parkinson's disease patients could have, sensory denervation, hyperhidrosis or sialorrhea ${ }^{[19]}$. Clinicians caring for Parkinson's disease patients should monitor for melanoma ${ }^{[20-22]}$. Skin moisture, cold limbs, and delayed healing of wounds ${ }^{[23-24]}$.

In late $60 \mathrm{~s}$, the German started to investigate the association between ADHD and atopic diseases ${ }^{[25]}$. Then in late $80 \mathrm{~s}$ and early 90 , they started to ask whether it is just a coincidence or there is a hypothetical background behind ${ }^{[26-28]}$ After circa $20 \mathrm{yrs}$, researchers started to dig behind such controversial issue to prove the robust association ${ }^{[29-41]}$. They proved the association between ADHD and atopic diseases among adults ${ }^{[29]}$ and children ${ }^{[30,34-35]}$. Articles published were of different designs as cross sectional design ${ }^{[30]}$, case control ${ }^{[34-35]}$, cohort studies ${ }^{[39]}$ or review $\operatorname{articles}^{[32,37]}$.

Atopic dermatitis (AD) is a common chronic inflammatory disease that is associated with significant psychosocial morbidity and a decrease in quality of life ${ }^{[29]}$. The most robust and recently published cohort study by Genuneit and colleagues ${ }^{[39]}$ proved the association of early atopic eczema(AE) with early ADHD. But, the association of early AE among children with late ADHD was not statistically significant. Also, the association of late AE with late ADHD was not proved. Cicek and colleagues $^{[29]}$ investigated the co-presence of ADHD in AD patients in the adult age group but in only a case control study design. Therefore, there is still a need to replicate cohort studies to (dis) prove such association.

Other primary psychiatric disorders as depressive and anxiety disorders have its repercussion on the psycho-dermatologic Disorders ${ }^{[42]}$ Depression may lead to acts of self-harm to the skin or nails, and up to $30 \%$ of patients at a dermatology clinic could be depressed especially those with acne or alope$\operatorname{cia}^{[43-45]}$.

\section{Conclusion}

To conclude, the link between the skin and the nervous system is uncontested. Psychotropic drugs for psycho-dermatologic lesions are often effective by themselves, or by adding other treatments. Other non-pharmacological interventions adopted in psychiatry as cognitive-behavioral therapy improves the treatment outcomes of skin lesions. A multidisciplinary approach to these complex problems often optimizes treatment response ${ }^{[42]}$.

\section{References}

1. Ghevariya,V., Singhal, S., Anand, S. The skin: a mirror to the gut. (2013) Int J Colorectal Dis 28(7): 889-913.

2. Vahora, R., Thakkar, S., Marfatia, Y. Skin, a mirror reflecting diabetes mellitus: A longitudinal study in a tertiary care hospital in Gujarat. (2013) Indian J Endocrinol Metab 17(4): 659-64.

3. Hofmann, B., Adam, A. C., Jacobs, K., et al. Advanced glycation end product associated skin autofluorescence: a mirror of vascular func-

Copy rights: (C2015 Afifi, M. This is an Open access article distributed under the terms of Creative Commons Attribution 4.0 International License. 
tion? (2013) Exp Gerontol 48(1): 38-44.

4. Shiel, S. Man in the mirror: research considerations for the care and appearance of men's skin. (2012) Br J Dermatol 166 Suppl 1:1.

5. Nordlind, K., Azmitia, E. C., Slominski, A. The skin as a mirror of the soul: exploring the possible roles of serotonin. (2008) Exp Dermatol 17(4): 301-11.

6 .Stiefelhagen, P. Recurrent blood blisters on hands and face. The skin is a mirror of the bone marrow. (2007) MMW Fortschr Med 149(19): 19 .

7. Abenavoli, L., Leggio, L., Proietti, I., et al. The skin as a mirror of small intestine. (2007) Recenti Prog Med 98(6): 339-346.

8. Phanuphak, N. Skin lesions: mirror images of oral lesion infections. (2006) Adv Dent Res 19(1): 69-72.

9. Zenz, J. The skin as a mirror of the soul. (1989) Dtsch Krankenpflegez 42(7): 422-425.

10. Bäurle, G. The skin as a mirror image of rheumatic diseases. (1982) ZFA (Stuttgart) 58(15): 821-6.

11. South, M. A. The skin as a mirror of the immune system. (1976) Cutis 18(1): 27-36.

12. Jones, F. A. The skin: a mirror of the gut. (1973) Geriatrics 28(4): 75-81.

13. Thambiah, A. S. The skin as a mirror reflecting internal malignancy. (1969) Indian J Dermatol 14(3): 51-63.

14. Schneider, W., Fischer, H. The skin as a mirror of internal diseases. (1966) Med Welt 50: 2695-700.

15. Beritić, T. The skin as a mirror. (1966) Lijec Vjesn 88(8): 979-981. 16. Ahmed, I., Cronk, J. S., Crutchfield, C. E $3^{\text {rd }}$, et al. Myeloma-associated systemic amyloidosis presenting as chronic paronychia and palmodigital erythematous swelling and induration of the hands. (2000) J Am Acad Dermatol 42(2 Pt 2): 339-342.

17. Herstowska, M., Komorowska, O., Cubała, W. J., et al. Severe skin complications in patients treated with antidepressants: a literature review. (2014) Postepy Dermatol Alergol 31(2): 92-97.

18. Newbold, P. C. Antidepressants and skin disease. (1988) Br Med J (Clin Res Ed) 296(6619): 379.

19. Gregory, R., Miller, S. Parkinson's disease and the skin. (2015) Pract Neurol pii: practneurol-2015-001107.

20. Ferreira, J. J., Neutel, D., Mestre, T., et al. Skin cancer and Parkinson's disease. (2010) Mov Disord 25(2): 139-48.

21. Inzelberg, R., Israeli-Korn, S. D. The particular relationship between Parkinson's disease and malignancy: a focus on skin cancers. (2009) J Neural Transm 116(11): 1503-1507.

22. Ferreira, J., Silva, J. M., Freire, R., et al. Skin cancers and precancerous lesions in Parkinson's disease patients. (2007) Mov Disord 22(10): 1471-1475.

23. Shindo, K., Kobayashi, F., Miwa, M., et al. Temporal prolongation of decreased skin blood flow causes cold limbs in Parkinson's disease. (2013) J Neural Transm 120(3): 445-451.

24. Beitz, J. M. Skin and wound issues in patients with Parkinson's disease: an overview of common disorders. (2013) Ostomy Wound Manage 59(6): 26-36.

25. Stüttgen, G., Nassabi, M., Herrmann, F. [On the influence of exposure to dry heat on the parotis-secretion with special attention to conditions in atopic dermatitis]. (1968) Arch Klin Exp Dermatol 231(3): 231-238.

26. Beyreiss, J., Roth, N., Beyer, H., et al. Coincidence of immune (atopic dermatitis) and behavioral (attention deficit) disorders in children: empirical data. (1988) Act Nerv Super (Praha) 30(2): 127-128.

27. Schwartz, L. B. Mast cell heterogeneity with special attention to cutaneous atopic disease. (1989) Allergy 44 Suppl 9: 35-40.
28. Roth, N., Beyreiss, J., Schlenzka, K., et al. Coincidence of attention deficit disorder and atopic disorders in children: empirical findings and hypothetical background. (1991) J Abnorm Child Psychol 19(1): 1-13. 29. Cicek, D., Kandi, B., Dertlioglu, S. B., et al. Investigation of attention deficit and hyperactivity disorder in adult patients with atopic dermatitis. (2009) Int J Psychiatry Clin Pract 13(4): 292-297.

30. Schmitt, J., Romanos, M., Schmitt, N. M., et al. Atopic eczema and attention-deficit/hyperactivity disorder in a population-based sample of children and adolescents. (2009) JAMA 301(7): 724-726.

31. Romanos, M., Gerlach, M., Warnke, A., et al. Association of attention-deficit/hyperactivity disorder and atopic eczema modified by sleep disturbance in a large population-based sample. (2010) J Epidemiol Community Health 64(3): 269-273.

32. Schmitt, J., Buske-Kirschbaum, A., Roessner, V. Is atopic disease a risk factor for attention-deficit/hyperactivity disorder? A systematic review. (2010) Allergy 65(12): 1506-1524.

33. Gee, S. N., Bigby, M. Atopic dermatitis and attention-deficit/hyperactivity disorder: is there an association? (2011) Arch Dermatol 147(8): 967-970.

34. Hak, E., de Vries, T. W., Hoekstra, P. J., et al. Association of childhood attention-deficit/hyperactivity disorder with atopic diseases and skin infections? A matched case-control study using the General Practice Research Database. (2013) Ann Allergy Asthma Immunol 111(2): 102-106.

35. Tsai, J. D., Chang, S. N., Mou, C. H., et al. Association between atopic diseases and attention-deficit/hyperactivity disorder in childhood: a population-based case-control study. (2013) Ann Epidemiol 23(4): 185-188.

36. Buske-Kirschbaum, A., Schmitt, J., Plessow, F., et al. Psychoendocrine and psychoneuroimmunological mechanisms in the comorbidity of atopic eczema and attention deficit/hyperactivity disorder. (2013) Psychoneuroendocrinology 38(1): 12-23.

37. Schmitt, J., Apfelbacher, C., Heinrich, J., et al. [Association of atopic eczema and attention-deficit/hyperactivity disorder - meta-analysis of epidemiologic studies]. (2013) Z Kinder Jugendpsychiatr Psychother 41(1): 35-42.

38. Fukunaga, N., Okada, Y., Konishi, Y., et al. Pay attention to valvular disease in the presence of atopic dermatitis. (2013) Circ J 77(7): 18621866.

39. Genuneit, J., Braig, S., Brandt, S., et al. Infant atopic eczema and subsequent attention-deficit/hyperactivity disorder--a prospective birth cohort study. (2014) Pediatr Allergy Immunol 25(1): 51-56.

40. Tsai, M. C., Lin, H. K., Lin, C. H., et al. Prevalence of attention deficit/hyperactivity disorder in pediatric allergic rhinitis: a nationwide population-based study. (2011) Allergy Asthma Proc 32(6): 41-46.

41. Pelsser, L. M., Buitelaar, J. K., Savelkoul, H. F. ADHD as a (non) allergic hypersensitivity disorder: a hypothesis. (2009 Pediatr Allergy Immunol 20(2): 107-112.

42. Shenefelt, P. D. Management of Psychodermatologic Disorders. Dermatology Nursing.

43. Gupta, M. A., Gupta, A. K. Depression and dermatological disorders. In J.Y.M. Koo \& C.S. Lee (Eds.). (2003) Psychocutaneous medicine 233-249.

44. Seyhan, M., Aki, T., Karincaoglu, Y., et al. Psychiatric morbidity in dermatology patients: Frequency and results of consultations. (2006) Indian Journal of Dermatology 51(1): 18-22.

45. Picardi, A., Abenia, D., Melchi, C.F., et al. Psychiatric morbidity in dermatological outpatients: an issue to be recognized. (2000) $\mathrm{Br} \mathrm{J}$ Dermatol 143(5): 983-991. 